\title{
PLATAFORMA INTERATIVA DE DECISÕES SOBRE REFÚGIO: ANÁLISE DE DADOS SOBRE VENEZUELANOS NO MARANHÃO
}

\author{
Guilherme Saldanha Santana ${ }^{1}$ \\ Roberto Carvalho Veloso ${ }^{2}$ \\ Thayara Silva Castelo Branco ${ }^{3}$
}

\section{Resumo:}

O presente ensaio tem por objetivo a análise da Plataforma Interativa de decisões sobre Refúgio desenvolvida pelo CONARE em cooperação interinstitucional com Acnur e o Ministério da Justiça e Segurança Pública do Governo do Brasil. Para tanto, uma percepção estratificada dos dados condicionará o espaço de análise quantitativa e qualitativa delimitando ao Estado do Maranhão e os processos deferidos de concessão de refúgio à venezuelanos pela plenária do CONARE. Assim será possível identificar a real eficiência da plataforma e sua consolidação e dados.

Palavras-chave: CONARE; Plataforma Interativa; Direitos Humanos; Refugiados;

Venezuelanos

\section{INTERACTIVE REFUGE DECISION PLATFORM: DATA ANALYSIS ON VENEZUELANS IN MARANHÃO.}

\begin{abstract}
:
This essay aims to analyze the Interactive Platform for decisions on Refuge, developed by CONARE in inter-institutional cooperation with UNHCR and the Ministry of Justice and Public Security of Brazil's Government. For this purpose, a stratified perception of the data will condition the space for quantitative and qualitative analysis delimiting the State of Maranhão and the procedures for granting asylum granted by the CONARE plenary. Thus, it will be possible to identify the real efficiency of the platform and its consolidation and data.
\end{abstract}

Keywords: CONARE; Interactive Platform; Human rights; Refugees; Venezuelan

\section{INTRODUÇÃO}

O presente trabalho tem como objetivo geral a análise sobre as Decisões de Refúgio no Estado do Maranhão consoante os dados extraídos da Plataforma Interativa de Decisões sobre

\footnotetext{
${ }^{1}$ Licenciado em História - UEMA. Bacharel em Direito - Universidade CEUMA. Pós-Graduado em Relações Internacionais PUCMINAS. Mestrando em Ciências Jurídicas - UAL/Lisboa. Doutorando em Ciências Jurídicas - UAL/Lisboa. Mestrando em Direito e Afirmação de Vulneráveis - Universidade CEUMA. Professor de História da Rede Pública do Estado do Maranhão. Professor Universitário de Direito Internacional. Advogado. Presidente da Comissão de Tecnologia da Informação OAB/MA.

2 Juiz Federal no Maranhão. Doutor em Direito pela Universidade Federal de Pernambuco. Mestre em Direito pela Universidade Federal de Pernambuco. Graduado em Direito pela Universidade Federal do Piauí. Professor Associado da Universidade Federal do Maranhão. Professor do Mestrado em Direito da Universidade CEUMA. Professor Colaborador da Universidade Autónoma de Lisboa - Portugal. Coordenador do Mestrado em Direito da UFMA. Membro da Academia Maranhense de Letras Jurídicas.

${ }^{3}$ Advogada. Doutora em Ciências Criminais - PUCRS, com área de pesquisa em Violência, Crime e Segurança Pública. Mestra em Ciências Criminais - PUCRS, com linha de pesquisa em Criminologia e Controle Social. Especialista em Ciências Criminais - CESUSC. Professora permanente do mestrado profissional em "direito e afirmação de vulneráveis" Universidade CEUMA.
} 
Refúgio $^{4}$, que foi consolidada através da contribuição interinstitucional entre o $\operatorname{CONARE}^{5}$, o Ministério de Justiça e Segurança Pública do Brasil e acompanhamento da ACNUR ${ }^{6}$.

Como indagação preliminar que norteia a presente pesquisa, tem-se: Em que medida a Plataforma Interativa de Decisões sobre Refúgio é útil e reflete com transparência a contabilização dos fluxos migratórios e entrada de venezuelanos no Estado do Maranhão?

A hipótese do trabalho é de que consolidação de dados oficiais realizada pela cooperação interinstitucional que pretende identificar os números de concessões de refúgio não reflete todos os tipos de entrada de estrangeiros no Estado brasileiro, ou pela falta de manejo do Estado ou pelos obstáculos de acesso sofridos pelos refugiados.

A cooperação interinstitucional permitiu publicação das decisões das plenárias do CONARE na rede - internet - tornando o acesso mais democrático e de fácil acesso, bem como contribuiu para edição e publicação da obra Refúgio em Números ${ }^{7}$ um dos relatórios organizado pela OBMigra ${ }^{8}$ sobre o fenômeno dos fluxos migratórios no país.

Através da extração dos dados referentes ao número de decisões de concessão de refúgio no Estado do Maranhão, pretende-se identificar as etnias que obtiveram a condição de refugiado, bem como estratificar por gênero, faixa etária e o motivo de inclusão, os indivíduos que tiveram a condição de refúgio concedida pelo CONARE.

Como metodologia será realizada uma análise qualitativa dos dados extraídos da Plataforma Interativa de Decisões sobre Refúgio, para explicação e interpretação do fenômeno dos fluxos migratórios mundiais nos últimos anos no Brasil, com ênfase no Estado do Maranhão, mesmo durante o contexto de Pandemia Covid-19.

A observação historiográfica inspirada em instrumentos internacionais que proferiram os direitos humanos até a formação do constructo axiológico da dignidade humana como norteadora dos direitos humanos internacionais - fundamentais - será utilizada como instrumento de reflexão sobre a crise de refugiados, Da mesma forma a análise das $5^{\mathrm{a}}$ e $6^{\mathrm{a}}$

\footnotetext{
${ }^{4}$ Disponível em:

https://app.powerbi.com/view?r=eyJrIjoiNTQ4MTU0NGItYzNkMi00M2MwLWFhZWMtMDBiM2I1NWVjM TY5IiwidCI6ImU1YzM3OTgxLTY2NjQtNDEzNC04YTBjLTY1NDNkMmFmODBiZSIsImMiOjh9

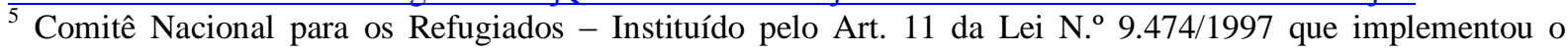
Estatuto dos Refugiados no Brasil.

${ }^{6}$ Alto-comissariado das Nações Unidas para os Refugiados - Agência da ONU em tutela dos direitos das pessoas em situação de refúgio pelo Mundo.

${ }^{7}$ Disponível em: https://www.justica.gov.br/seus-direitos/refugio/refugio-em-numeros

8 Observatório das Migrações Internacionais - criado em 2013 por Termo de Cooperação N. ${ }^{\circ}$ 04/2013 entre Ministério do Trabalho, Conselho Nacional de Imigração e a Universidade de Brasília (UNB).
} 
edições da publicação Refúgio em Números servirão de referência para entender a realidade supra manifestada.

E ainda, será observada a entrada massiva de venezuelanos no Brasil, e no Maranhão, consoante o reconhecimento da situação de "Grave e Generalizada Violação de Direitos Humanos na Venezuela"9, efetivada pelo CONARE em método comparativo com números estratificados da Plataforma Interativa de Decisões sobre Refúgio no Estado de Solicitação para identificar se os números encontrados refletem nas concessões de refúgio ao Estado do Maranhão.

\section{AFIRMAÇÃO DA DIGNIDADE HUMANA, UM - NOVO - MUNDO CONTEMPORÂNEO.}

A historiografia tradicional ocidental perfaz a secção cronológica dos acontecimentos históricos em períodos desde a pré-história (anterior a escrita), idade antiga (civilização clássica), idade média (feudalismo), idade moderna (a era das revoluções) e idade contemporânea (sociedade da informação).

Entretanto, temos mantido uma consoante preferência pela divisão do da história ocidental a partir da interpretação de Alvin Toffler (1980) e suas ondas de revolução social que partem desde a revolução agrícola (primeira onda), passando revolução industrial (segunda onda) e chegando até a revolução da comunicação e da informação (terceira onda), assim observam Santana e Santos (2021, p. 312).

Em nossos últimos ensaios um esforço significativo tem sido realizado para identificarmos na academia uma identificação da expressão “- novo - Mundo contemporâneo" (SANTANA, 2020, p.156), caracterizando uma sociedade internacional reflexa de escalas de desenvolvimento diversas, consoante não apenas a coexistência das teoria de ondas supramencionada, como também a coexistência das dimensões dos direitos humanos internacionais (SANTANA; SANTOS, 2020, p.14).

Para tanto, é defesa constante em nossas reflexões a percepção de coexistência das ondas de evolução social (CARDOSO, 1996, p.15), vez que a história das sociedades não

\footnotetext{
${ }^{9}$ Em 14 de junho de 2018, o CONARE decidiu reconhecer a situação de "grave e generalizada violação de Direitos Humanos" na Venezuela, com fundamento no inciso III do Art. $1^{\circ}$ da Lei N$^{\circ}$ 9.474/97
} 
reflete um contexto cronológico prático, progressivo e uno, sendo passível identificar que sociedades agrícolas subsistem ao lado de sociedades que viveram suas diversas revoluções industriais.

Propor um - novo - Mundo contemporâneo parte da análise exaustivamente debatida pela doutrina da afirmação dos direitos humanos internacionais no contexto do pós-segunda guerra mundial diante o constructo axiológico da dignidade humana e a coexistência dos mesmos em suas dimensões, sob a perspectiva de Norberto Bobbio (2020) que os direitos humanos são históricos.

As declarações de independência dos Estados Unidos da América de 1776 e da assembleia constituinte francesa - Declaração dos Direitos do Homem e do Cidadão de 1789 - convidam o debate da internacionalização dos direitos humanos, inspiradas na prestação negativa do Estado, bem como afirmação da liberdade, inspirando uma contraposição ao antigo regime absolutista - ancien régime.

Cumpre destacar que as declarações sofrem influências recíprocas, vez que seus protagonistas idealizadores - Thomas Jefferson e Marquês de Lafayette, amigos pessoais muito provavelmente estiveram juntos em Paris delineando uma declaração antes mesmo da queda da bastilha. (HUNT, 2009, p. 14)

Se a liberdade foi inspiração primordial à declaração americana, serviu como alicerce paralelo à igualdade e posteriormente à fraternidade - em 1848 - para declaração francesa completando a tríade representativa tão emblemática dos direitos humanos "liberte, igualité e fraternitê", até a assimilação da dignidade. (PIRES, 2016, p. 35)

Entretanto, o start histórico dos direitos humanos internacionais delimitado à este ensaio perfaz a Declaração Universal dos Direitos Humanos de 1948 - DUDH - e esta, resposta contundente às atrocidades cometidas durante a segunda guerra mundial ${ }^{10}$, trazendo ao protagonismo dos atores internacionais os indivíduos, consolidando a dignidade humana, já

\footnotetext{
${ }^{10}$ Sobre a internacionalização dos direitos humanos importante observar: "A internacionalização dos direitos humanos constitui, assim, um movimento extremamente recente na história que surgiu a partir do pós-guerra, como resposta às atrocidades e aos horrores cometidos durante o nazismo. Apresentando o Estado como o grande violador dos direitos humanos, a Era Hitler foi marcada pela lógica da destruição e da descartabilidade da pessoa humana, o que resultou no extermínio de onze milhões de pessoas. O legado do nazismo foi condicionar a titularidade de direitos, ou seja, a condição de sujeitos de direitos, à pertinência a determinada raça - a raça pura ariana." (PIOVESAN, 2009, p. 120).
} 
inaugurada pela Carta das Nações Unidas de 1945. Paulo Portela (2020) destaca o reconhecimento da dignidade no cenário internacional a partir da declaração de $1948^{11}$.

O pós-segunda guerra mundial desperta os ordenamentos jurídicos internacionais e internos ao reconhecimento da dignidade humana como valor axiológico, cabível a tutela dos indivíduos - aquilo que os diferencia das coisas, que possuem um preço (COMPARATO, 2015, p. 35). Ingo Sarlet (2019) ainda destaca que assimilação da dignidade aos direitos humanos é fim em si mesma, conduz a autonomia do indivíduo ${ }^{12}$.

Ainda que parte da doutrina reitere a dignidade como da "pessoa humana" atribuindo a esta um status mais emblemático da condição humana, a opção por ora utilizada delimita-se a habitualidade da dignidade humana, como expressão ampla e autossuficiente.

A reflexão provocada em caráter raso, tem por objetivo apenas não delimitar a dignidade humana à pessoa, mas estender o universo da dignidade, atribuindo o caráter axiológico dos direitos humanos à transversalidade de atores e direitos existentes, bem como por existir, vez observada a historicidade dos direitos humanos e sua afirmação em escalas diferentes.

E então, a dignidade humana, consolidada como "superprincípio" constitucional. Flávia Piovesan (2009), observa contundentemente à dignidade humana o caráter inaugural e fomentador dos direitos humanos, dentro dos ordenamentos constitucionais do - novo Mundo contemporâneo. ${ }^{13}$

\footnotetext{
${ }^{11}$ Sobre a DUDH, pertinente percepção: "A Declaração é baseada em princípios que orientam a aplicação do Direito Internacional dos Direitos Humanos como um todo, como o reconhecimento da dignidade inerente a todos os membros da família humana e de seus direitos iguais e inalienáveis como o fundamento da liberdade, da justiça e da paz no mundo; o fato de que o desrespeito pelos direitos do homem resultou em atos bárbaros; o entendimento de que a proteção da liberdade e do bem-estar do ser humano adquiriram o caráter de prioridade na ordem internacional; e o compromisso dos Estados e das Nações Unidas em promover aplicação dos direitos humanos." (PORTELA, 2020, p. 1019)

${ }^{12}$ Sobre a dignidade humana lição indispensável: "Temos por dignidade da pessoa humana a qualidade intrínseca e distintiva de cada ser humano que o faz merecedor do mesmo respeito e consideração por parte do Estado e da comunidade, implicando, neste sentido, um complexo de direitos e deveres fundamentais que assegurem a pessoa tanto contra todo e qualquer ato de cunho degradante e desumano, como venham a lhe garantir as condições existenciais mínimas para uma vida saudável, além de propiciar e promover sua participação ativa corresponsável nos destinos da própria existência e da vida em comunhão dos demais seres humanos" (SARLET, 2019, p. 70-71)

${ }^{13}$ E ainda sobre a dignidade humana: "Assim, seja no âmbito internacional, seja no âmbito interno (à luz do Direito Constitucional ocidental), a dignidade da pessoa humana é princípio que unifica e centraliza todo o sistema normativo, assumindo especial prioridade. A dignidade humana simboliza, desse modo, verdadeiro superprincípio constitucional, a norma maior a orientar o constitucionalismo contemporâneo, nas esferas local e global, dotando-lhe de especial racionalidade, unidade e sentido" (PIOVESAN, 2009, p. 31)
} 


\section{ORDENAMENTOS INTERNACIONAIS E INTERNOS SOBRE REFUGIADOS: A CRISE MIGRATÓRIA DE VENEZUELANOS.}

Consoante a percepção da dignidade como constructo axiológico dos direitos humanos internacionais é imperioso observar o hodierno contexto de fluxos migratórios de refugiados na condição de vulnerabilidade que atinge o espaço doméstico brasileiro.

A Resolução da Assembleia Geral das Nações Unidas A/70/L.1 - Transformando o Nosso Mundo: A Agenda 2030 para o Desenvolvimento Sustentável - foi um plano de ação adotado em 21 de setembro de 2015, dividido em 17 Objetivos de Desenvolvimento Sustentável (ODS) para promover o desenvolvimento sustentável, a dignidade e erradicar a pobreza no Mundo.

Em sua ODS 10 destaca o desafio dos fluxos migratórios contemporâneos, observando a necessidade do planejamento de medidas que possam permitir um fluxo ordenado e responsável que garanta a segurança das pessoas. Da mesma forma a ODS 8 identifica a necessidade de adequação no mercado de trabalho dos migrantes.

Ao tratarmos da situação de refúgio, não podemos partir de um pressuposto de escolha de indivíduos que decidem deixar o seu país, mas pelo contrário, fica bem definido o conceito do Estatuto dos Refugiados de 1951, efetivamente expresso ainda em seu artigo primeiro:

“Art. $1^{\text {o }}$ Será reconhecido como refugiado todo indivíduo que:

I - devido a fundados temores de perseguição por motivos de raça, religião, nacionalidade, grupo social ou opiniões políticas encontre-se fora de seu país de nacionalidade e não possa ou não queira acolher-se à proteção de tal país;

II - não tendo nacionalidade e estando fora do país onde antes teve sua residência habitual, não possa ou não queira regressar a ele, em função das circunstâncias descritas no inciso anterior;

III - devido a grave e generalizada violação de direitos humanos, é obrigado a deixar seu país de nacionalidade para buscar refúgio em outro país.” 
Jorge Miranda (2016, p. 7) bem leciona que a observação da condição de refúgio pelos "Estado de Direito" - por assim se classificarem - é condição de asilo, pertinente a confirmação da comunidade internacional. ${ }^{14}$

O Estado de Direito - identificado como tipicamente liberal por José Afonso da Silva (2020, p. 114) - compõe um processo histórico evolutivo ocidental, perpassando pelo Estado Social de Direito, até adentrarmos ao Estado Democrático de Direito, caracterizando primeiramente o Estado como democrático, reflexo de uma resposta político-social aos eventos que encerraram a segunda grande guerra.

Conforme supramencionado o - novo - Mundo contemporâneo - reflexo de uma sociedade da informação e da globalização catalisada pelas novas tecnologias de informação e comunicação, principalmente pela internet - reafirma as características de universalidade, indivisibilidade e interdependência dos direitos humanos internacionais, e portanto, a obrigação dos Estados ratificadores da Carta das Nações Unidas de garanti-los à todos os indivíduos.

Ainda que haja distinção formal no caput do artigo $5^{\circ}$ da Constituição da República Federativa do Brasil de 1988 entre estrangeiros residentes e não-residentes no Brasil, bem contrapõe Cristiane Lopes (2012, p. 42-43), não apenas refirmando a defesa da Dignidade Humana no artigo $1^{\circ}$, mas complementando com o artigo $3^{\circ}$ do texto constitucional, que indica a promoção ao bem de todos sem distinção e continua no artigo $4^{\circ}$ com a concessão de asilo político e a formação da comunidade da América Latina.

E, se a Declaração Universal de Direitos Humanos reafirma o constructo axiológico da dignidade, protege também o direito de asilo em outros países a todos os indivíduos que se sentirem perseguidos em seus próprios Estados (artigo 14).

\footnotetext{
${ }^{14}$ Sobre a aceitação de refugiados no Estado de Direito destaca-se: "Se, em todas as épocas, o refúgio para ou noutra terra tem sido o último recurso dos perseguidos pelo poder político ou por qualquer outro poder ou dos atingidos por qualquer forma de sofrimento ultrapassável, apenas nos dois últimos séculos e meio, ele aparece formalmente consagrado em textos jurídicos-formais sob a fora de direito de asilo, seja por um imperativo de uma maior consciência dos direitos das pessoas seja por um imperativo de solidariedade.

Assim como um Estado de Direito não pode consentir a expulsão ou banimento de um seu cidadão, também ele tenderá naturalmente a acolher os estrangeiros e apátridas que precisem de proteção, ainda quando haja no país situações de crise ou manifestações de xenofobia. E assim como se vai verificando a progressiva institucionalização da comunidade internacional, também esta leva a que os refugiados constituam preocupação de não poucas convenções declarações e outros textos internacionais. Por isso, o direito de asilo consta na Declaração Universal dos Direitos do Homem e existe um Alto-Comissariado das Nações Unidas para os Refugiados." (MIRANDA, 2016, p.07)
} 
Não obstante, o Estatuto dos Refugiados de 1951, bem como o Protocolo deste em 1967, a Convenção da Organização da Unidade Africana de 1969 e a Declaração de Cartagena de 1984 ampliam o status da condição de refugiado. (SILVA; CAVALCANTI; et al. 2021, pp. 05-06)

O Brasil rompe com o Estatuto do Estrangeiro, legislação reflexa dos governos militares para assumir um instrumento normativo humanizado: a Lei de Migração N. ${ }^{\circ}$ 13.445/2017 e seu decreto regulamentador N. ${ }^{\circ}$ 9.199/2017.

Passível observar que os instrumentos legais supramencionados confirmam a responsabilidade internacional dos Estados de recepção aos indivíduos em condição de vulnerabilidade e de violação de seus direitos humanos, bem como o ordenamento jurídico do pátrio, seja na norma constitucional seja nas normas inferiores.

Uma vez dispostos os instrumentos normativos orientadores de nossa perquirição, cumpre mencionar o boom desenfreado de fluxos migratórios de venezuelanos ao Brasil, ocasionando o reconhecimento em 14 de junho 2018 da "grave e generalizada violação de direitos humanos" pelo CONARE (SILVA; CAVALCANTI; Et. Al. 2020).

Em 2019 foram 53.573 (cinquenta e três mil quinhentos e setenta e três) venezuelanos que fizeram o pedido de reconhecimento de refúgio e em 2020, mesmo durante o contexto de Pandemia Covid-19 foram 17.385 (treze mil trezentos e oitenta e cinco) pedidos (SILVA; CAVALCANTI; Et. Al. 2020).

A crise humanitária na República Bolivariana da Venezuela já era anunciada mundialmente, chegando o Estado a ser suspenso do MERCOSUL ${ }^{15}$ desde 5 de agosto de 2017, por descumprir as determinações dos artigos $4^{\circ}$ e $5^{\circ}$ do Protocolo de Ushuaia, ratificado no Brasil pelo Dec. N. ${ }^{\circ}$ 4.210/2002 que indica medida de suspensão do MERCOSUL ao Estado em que as consultas sobre a manutenção da ordem democrática sejam infrutíferas.

De tal maneira, é público e notório em todo contexto social pátrio inúmeros venezuelanos em condição de vulnerabilidade, dispostos pelos mais diversos espaços públicos do Brasil, o que não é diferente no Estado do Maranhão.

\footnotetext{
${ }^{15}$ Mercado Comum do Sul
} 


\section{VENEZUELANOS NO MARANHÃO: CONCESSÕES DE REFÚGIO PELO CONARE.}

A Plataforma Interativa de Decisões sobre Refúgio ${ }^{16}$ permite uma análise específica sobre os processos de concessão de refúgio, estratificando diversas variáveis para identificar dados importantes sobre os refugiados, indicando o gênero, nacionalidade, Estado onde foi demandado o processo de concessão de refúgio.

Por tal motivo foi o recorte do presente ensaio para identificação das decisões plenárias do CONARE sobre as concessões de refúgio, com o objetivo de observar se o fenômeno dos fluxos migratórios de venezuelanos nas fronteiras do Brasil seria acompanhada no Estado do Maranhão.

O recorte espacial, permite reflexões sobre os dados oficiais coletados na Plataforma para o presente ensaio com o objetivo de instruir uma análise mais específica sobre o grupo de refugiados dentro do Estado do Maranhão, vez que é perceptível o aumento da quantidade de indigentes estrangeiros nos espaços públicos.

O projeto de cooperação para análise das decisões de Refúgio no Brasil ${ }^{17}$ surgiu em uma parceira entre a Coordenação-Geral do Comitê Nacional para os Refugiados (CGConare) do Ministério da Justiça e Segurança Pública (MJSP) e a agência da ONU para refugiados (ACNUR) proporcionando uma análise e publicação e acompanhamento dos dados sobre decisões dos processos de refúgio.

As decisões sobre a condição de refúgio no Estado brasileiro podem ocorrer em três esferas, pelo Conare (reconhecimento, indeferimento, cessação, perda, extinção e arquivamento), pela Coordenação-Geral do Conare (extinção e arquivamento de alguns casos conforme Resolução normativo n. ${ }^{\circ} 18$ do Conare) e pelo Ministro de Estado da Justiça e Segurança Pública (decide os recursos das decisões do Comitê Nacional para os Refugiados).

Necessária uma breve apresentação da interface da Plataforma para compreensão da posterior extração de dados sobre o Estado do Maranhão.

\footnotetext{
${ }^{16}$ Disponível no endereço: https://app.powerbi.com/view?r=eyJrIjoiNTQ4MTU0NGItYzNkMi00M2MwLWFhZWMtMDBiM2I1NWVjM TY5IiwidCI6ImU1YzM3OTgxLTY2NjQtNDEzNC04YTBjLTY1NDNkMmFmODBiZSIsImMiOjh9

17 Disponível no endereço: https://www.acnur.org/portugues/wp-content/uploads/2019/07/Projeto-ACNURConare_VFINAL.pdf
} 
Para tanto, a página 02 do dashboard apresenta dados nacionais que correspondem a 73.513 (setenta e três mil quinhentos e treze) decisões sobre refúgio dentro do Estado brasileiro de 109 (cento e nove) nacionalidades diferentes.

Da mesma forma a página 03 o analysis permite uma seleção de filtros que especificam ainda mais os processos de concessão de refúgio permitindo a seleção de gênero, ano, tipo da decisão, estado de solicitação, status da decisão, nacionalidade, faixa etária e motivo da inclusão.

Por fim, na dashboard da página 04 temos a consolidação dos dados sobre os Recursos das Decisões do CONARE em gráficos que proporcionam uma visualização mais dinâmica da intenção da plataforma, indicando um projeto robusto e inovador.

Ao fazermos a filtragem adequada ao presente trabalho, na dashboard 02, foi selecionado o Estado de solicitação como Maranhão, o que reduziu o universo para 30 (trinta) decisões sobre a solicitação de refúgio, sendo possível observar universo de nacionalidades foi reduzido para apenas 6 (seis) diferentes etnias.

Ainda na dashboard 02 foi possível extrair que 5 (cinco) casos foram indeferidos e outros 13 (treze) casos foram encerrados, sendo que destes 1 (um) arquivado e 12 (doze) extintos. Apenas 12 (doze) casos possuem o status de reconhecidos.

Como primeira análise indicamos a nacionalidade cubana como a maior demanda dos processos de refúgio no Estado do Maranhão.

Contudo, ao filtrarmos apenas os processos elegíveis, de concessão de refúgio, observamos 5 (cinco) venezuelanos, 3 (três) cubanos, 2 (dois) salvadorenhos, 1 (um) angolano e 1 (um) egípcio.

$\mathrm{O}$ que indicou aproximadamente $42 \%$ (quarenta e dois por cento) dos processos de concessão de refúgios no Estado do Maranhão à venezuelanos, contra quase 92\% (noventa e dois por cento) de concessões se observado todo o Brasil.

Outros dados importantes extraídos importante para identificação dos refugiados venezuelanos foi a faixa etária entre 18-29 anos que ocupa aproximadamente 66\% (sessenta e seis por cento) no Maranhão e aproximadamente $44 \%$ (quarenta e quatro por cento) no Brasil.

Quanto a concessão de refúgio por gênero foi observado um relativo desequilíbrio os indivíduos que obtiveram a condição de refúgio elegível no Estado do Maranhão e no Brasil, correspondendo aproximadamente $10 \%$ (dez por cento) de diferença favorável aos homens. 
Quanto ao motivo da inclusão na condição de refúgio, podemos apontar que no Estado do Maranhão todos os 5 (cinco) casos reconhecidos da condição de refúgio tiveram como motivo grave e generalizada de violação de direitos humanos. Enquanto em no universo Brasil dos 45.725 (quarenta e cinco mil setecentos e vinte cinco) venezuelanos, 11 (onze) tiveram como motivação grupo social, 65 (sessenta e cinco) opinião política e 45.649 (quarenta e cinco mil seiscentos e quarenta e nove) venezuelanos também tiveram como motivo de inclusão grave e generalizada de violação de direitos humanos.

Ao recortarmos os dados dispostos na Plataforma Interativa de Decisões sobre Refúgio, utilizando a filtragem passo à passo supramencionada, encontramos apenas um pequeno grupo de 5 (cinco) venezuelanos com a condição de refúgio legalizada, refletindo um alerta ao presente ensaio: a Plataforma é capaz de reproduzir a realidade social observada nos espaços públicos do Estado brasileiro?

Contudo, não importa a perquirição em desvalorizar a Plataforma, mas pelo contrário, esta é fundamental para consolidar dados oficiais e contrapor os mesmos a pesquisas de campo que possam identificar possíveis subnotificações, tal qual as situações irregulares de entrada no Estado brasileiro.

Importante conhecer o Projeto de Cooperação na Análise das Decisões de Refúgio no Brasil, a publicação Refúgio em Números organizada pela OBMigra para identificar os dados extraídos da Plataforma.

\section{1 - Projeto de Cooperação na Análise das Decisões de Refúgio no Brasil.}

O Comitê Nacional para Refugiados - CONARE - é um órgão de deliberação coletiva, no âmbito do Ministério da Justiça e Segurança Pública, consoante o artigo 11 da Lei 9.474/97, que introduz ao espaço normativo pátrio o Estatuto dos Refugiados.

Sua composição está definida no artigo 14 da mencionada lei, bem como seu funcionamento está disposto nos artigos 15 e 16, definido o quórum 4 (quatro) membros, deliberando sempre por maioria simples e em caso de empate com voto decisivo do presidente do Comitê. O Alto Comissariado das Nações Unidas para Refugiados (ACNUR) é observado pela própria lei como membro convidado do Comitê, com direito a voz, mas não à voto. 
Ao Comitê cabe as análise e decisões sobre os processos que demandam a condição de refúgio dentro do Estado brasileiro e, portanto, a multilateralidade dos membros que o compõe em ministérios estratégicos do governo.

Cumpre destacar que em 15 de setembro de 2019 foi implementado o Sisconare ${ }^{18}$, com o objetivo de otimizar as demandas de os processos de solicitação de refúgio, tornando mais fácil o primeiro momento de análise de dados e permitindo o acompanhamento pelo solicitante da condição de refúgio, permitindo até mesmo a retificação documental.

O Projeto de Cooperação para Análise das Decisões de Refúgio no Brasil entre o CONARE, o Ministério da Justiça e Segurança Pública e a ACNUR tem com pressuposto uma análise de dados referente as decisões de refúgio no Estado brasileiro, em uma análise individual de cada caso para assimilação na Plataforma Interativa acima mencionada.

Compete um breve recorte na metodologia aplicada ao projeto que definiu as decisões tomadas pelo CONARE em 5 vertentes: 1. Casos reconhecidos pela elegibilidade; 2. Casos indeferidos pela elegibilidade; 3. Casos de perda da condição de refugiado; 4. Casos da cessação da condição de refugiado; 5 . Outros casos encerrados - incluindo os arquivados. ${ }^{19}$

Como resultado do Projeto foi possível não apenas estabelecer terminologias e definições sobre os processos de concessão de refúgio provocados ao Conare, mas estabelecer um banco de dados de grande valor consolidado na Plataforma Interativa de Decisões sobre Refúgio.

\section{2 - Refúgio em Números.}

A publicação Refúgio em Números, tem com propósito uma análise multilateral de $\operatorname{dados}^{20}$ sobre os fluxos migratórios que culminam com a chegada dos refugiados no território brasileiro, observando não apenas os processos de concessão, mas políticas públicas de atendimento aos refugiados.

18 Portal de Acesso para solicitação da Condição de Refúgio no Estado Brasileiro. Endereço: https://agenciabrasil.ebc.com.br/justica/noticia/2019-09/pedidos-de-refugio-no-brasil-serao-feitos-somente-pelainternet

19 Disponível no endereço: https://www.acnur.org/portugues/wp-content/uploads/2019/07/Projeto-ACNURConare_VFINAL.pdf

20 Realizados pelo Observatório da Migrações Internacionais (OBMigra) Disponível em: https://portaldeimigracao.mj.gov.br/images/dados/relatorioanual/2020/OBMigra_RELAT\%C3\%93RIO_ANUAL_2020.pdf 
Contudo, a Publicação serve de amparo para presente pesquisa na contraposição entre as $5^{\mathrm{a}}$ e $6^{\mathrm{a}}$ edições, que apresentam contundente abismo nas solicitações de refúgio de venezuelanos ao Estado brasileiro, aparente contexto da Pandemia Covid-19.

Enquanto em 2019 foram solicitadas a condição de refúgio por 82.552 (oitenta e dois mil quinhentos e cinquenta e dois) estrangeiros em 2020 o número de solicitantes caiu para 28.899 (vinte e oito mil oitocentos e noventa e nove) estrangeiros, uma redução de $65 \%$ (sessenta e cinco por cento) dos pedidos.

Convém estratificar ainda mais a análise de dados, em 201953.713 (cinquenta e três mil setecentos e treze) de todos os pedidos de concessão de refúgio eram de estrangeiros de nacionalidade venezuelana enquanto em 2020, 17.385 (dezessete mil trezentos e oitenta e cinco) venezuelanos pediram a concessão de refúgio.

Para o presente é suficiente a percepção que a edição Refúgio em Números apresenta uma realidade mundial dos fluxos migratórios, bem como indica que no caso brasileiro a recepção de venezuelanos é considerável quando contraposta à outras nacionalidades, uma vez já reconhecido pelo próprio CONARE a situação de grave e generalizada violação de direitos humanos naquele Estado.

\section{CONSIDERAÇÕES FINAIS.}

Os dados recortados da Plataforma Interativa de Decisões sobre o Refúgio sobre o Estado do Maranhão, indicam apenas um pequeno número de refugiados.

As considerações finais coadunam com a hipótese inaugural de falibidade dos dados para refletir a situação dos refugiados venezuelanos no Maranhão, vez que o universo encontrado pela filtragem da plataforma é pífio e não reproduz a realidade.

Contudo, o projeto pode ser considerado embrionário e de grande valia para pesquisas políticas públicas e mesmo para o conhecimento da sociedade civil de uma realidade cada vez mais perceptível no espaço urbano pátrio, consoante uma melhor identificação de estrangeiros que não tiveram acessibilidade ao processo de solicitação de refúgio. 
As inquietudes atingem novas provocações: Todos os nacionais venezuelanos perpassaram pelo processo de solicitação da condição de refúgio? A concessão ao estrangeiro da condição de refugiado, minora sua vulnerabilidade?

A reflexão sobre os dados, infere a qualidade destes para o interesse da pesquisa, nem sempre o caráter oficial permite uma fidelidade do que é apresentado prejudicando start inaugural das perquirições do pesquisador.

Portanto, a convicção da escolha inaugural reflete o propósito de observar a coleta de dados, bem como sua disposição em Plataforma Interativa de fácil acesso da rede, e assim consideramos:

A Plataforma Interativa de decisões sobre Refúgio é uma ferramenta inovadora de aglutinação de dados sobre os processos de refúgio no CONARE, permitindo reflexões multilaterais ao poder público, ao setor privado, à Universidades do público que está sendo acolhido pelo Estado brasileiro, conduzindo a construção de políticas públicas e de responsabilização social comum dos cidadãos pátrios;

O Governo Federal aplica metodologia arrojada em parceria com a Acnur, observando o disposto no Estatuto do Refugiado, garantindo uma política humanitária, reafirmada pela Lei de Migração, entretanto a delimitação da coleta de dados aos processos de solicitação de refúgio, desconsidera uma cifra oculta de indivíduos estrangeiros que não inauguraram este processo;

Assim, os dados extraídos sobre as concessões de refúgio que tem Estado Solicitante o Maranhão devem ser contrapostos à outras bases de dados, para análises transversais que permitam observar o real impacto da chegada de estrangeiros no Estado, bem como as políticas de acolhimento que podem ser adotadas pelo poder público e pela Sociedade Civil.

\section{REFERÊNCIAS.}

BOBBIO, Norberto - A Era dos Direitos. Rio de Janeiro: Ed. LTC, 2020.

CARDOSO, Ciro Flamarion - No limiar do Século XXI. In Revista Tempo (Federal Fluminense). Rio de Janeiro. Vol.1 nº 2, 1996. p. 7-30. 
CAVALCANTI, L; OLIVEIRA, T.; MACEDO, M., Imigração e Refúgio no Brasil. Relatório Anual 2020. Série Migrações. Observatório das Migrações Internacionais; Ministério da Justiça e Segurança Pública/ Conselho Nacional de Imigração e Coordenação Geral de Imigração Laboral. Brasília, DF: OBMigra, 2020.

COMPARATO, Fabio Konder - A afirmação histórica dos Direitos Humanos. 12a São Paulo: Ed. Saraiva Educação, 2019.

DUPUY, René-Jean - O Direito Internacional. Coimbra: Ed. Coimbra, 1993.

HUNT, Lynn - A invenção dos direitos humanos; uma história. São Paulo: Ed. Companhia das Letras, 2009.

LOPES, Cristiane Maria Sblaqueiro - O direito a não descriminação dos estrangeiros. In Boletim Científico - Escola Superior do Ministério Público da União. Brasília. Ano 11, N. 37, edição especial, 2012. p. 37-63.

MARTINS, Ana Maria Guerra - Direito Internacional dos Direitos Humanos. Coimbra: Ed. Almedina, 2017.

MIRANDA, Jorge - Curso de Direito Internacional. 6. Ed. Cascais: Ed. Principia, 2016.

MIRANDA, Jorge - Direito de asilo e refugiados na ordem jurídica portuguesa. 1. Ed. Lisboa: Ed. Universidade Católica, 2016.

NETTO, Menelick de Carvalho; SCOTTI, Guilherme - Os direitos fundamentais e a (in)certeza do direito: a produtividade as tensões principiológicas e a superação do sistema de regra. Belo Horizonte: Ed. Fórum, 2012.

PIOVESAN, Flávia - Direitos humanos e o direito constitucional internacional. 10. Ed. São Paulo: Ed. Saraiva, 2009.

PIOVESAN, Flávia - Declaração Universal de Direitos Humanos e a Constituição Brasileira de 1988. In: GOVANNETTE, Abdrea (org.). 60 anos da Declaração Universal dos Direitos Humanos: conquistas do Brasil. Brasília: Fundação Alexandre Gusmão, 2009, p.184. 
PIRES, Alex Sander Xavier - Constitucionalismo Luso Brasileiro - leitura normativa no âmbito do domínio da lei e da humanização das relações. Rio de Janeiro: Ed. Pensar Justiça, 2017.

PIRES, Alex Sander Xavier - Fluxos migratórios forçados e cultura de paz: um contributo hipotético baseado na educação como pilar da democracia e na solução alternativa à crise do estado assistencialista. In Revista Galileu (Revista de Direito e Economia). Lisboa. Ed. Ratio Legis, 2018. p. 64-85.

PIRES, Alex Sander Xavier; TRINDADE, Carla Dolezel; FILHO, Simão Asnar - Súmulas Vinculantes e Liberdades Fundamentais. Rio de Janeiro: Ed. Pensar Justiça, 2016.

PORTELA, Paulo Henrique Gonçalves - Direito Internacional Público e Privado. 9. Ed. Salvador: Ed. JusPODIVM, 2017.

QUEIROZ, Cristina - Direito Constitucional Internacional. Lisboa: Ed. Petrony, 2016.

QUEIROZ, Cristina - Poder Constituinte, Democracia e Direitos Fundamentais: uma via constitucional para a Europa? Coimbra: Ed. Coimbra, 2013.

SANTANA, Guilherme Saldanha - Direito de Esquecimento: intimidade $\mathbf{x}$ liberdade de informação In Cibernética Jurídica: Estudos sobre Direito Digital Claudio Joel Brito Lóssio Luciano Nascimento, Rosangela Tremel (Organizadores). - Campina Grande: EDUEPB, 2020, pp. 155-172.

SANTANA, Guilherme Saldanha - O Grupo de Trabalho sobre Governança da Internet da ONU e sua influência nas normas de copyright nos Estados Unidos da América, União Européia e Brasil. Minas Gerais: Pontifícia Universidade Católica de Minas Gerais, 2007. 21 f. Projeto de Conclusão de Especialização em Relações Internacionais.

SANTANA, Guilherme Saldanha; SANTOS, Diogo de Almeida Viana dos Santos - O Jornalismo Mediador: Responsabilidade Social em Informar In Juscibernética: volume 1: Direito, gestão, tecnologia, governança e sociedade [livro eletrônico]. Cláudio Joel Brito Lóssio...[et. al.] (Organizadores) - Campina Grande: EDUEPB, 2021, pp. 311-337.

SANTANA, Guilherme Saldanha; SANTOS, Diogo de Almeida Viana dos Santos - Poder Vinculante da Declaração Universal dos Direitos Humanos In Direito, democracia e 
desenvolvimento. In Maynara Costa de Oliveira Silva, Renata Caroline Pereira Reis (organizadoras) - Curitiba: CRV, 2020, pp. 13-27.

SARLET, Ingo Wolfgang - A eficácia dos direitos fundamentais: uma teoria dos direitos fundamentais na perspectiva constitucional, 10.ed. rev. atual. ampl., Porto Alegre: Ed. Livraria do Advogado 2009.

SARLET, Ingo Wolfgang - Dignidade (da pessoa) humana e direitos fundamentais na Constituição Federal de 1988, 10.ed. rev. atual. ampl., Porto Alegra: Ed. Livraria do Advogado, 2019.

SILVA, G. J; CAVALCANTI, L; OLIVEIRA, T; MACEDO, M. Refúgio em Números, 5a Ed. Observatório das Migrações Internacionais; Ministério da Justiça e Segurança Pública/ Comitê Nacional para os Refugiados. Brasília, DF: OBMigra, 2020.

SILVA, G. J; CAVALCANTI, L; OLIVEIRA, T; COSTA, L. F. L; MACEDO, M. Refúgio em Números, 6a Edição. Observatório das Migrações Internacionais; Ministério da Justiça e Segurança Pública/ Comitê Nacional para os Refugiados. Brasília, DF: OBMigra, 2021.

SILVA, José Afonso da - Curso de Direito Constitucional Positivo. 43ª ed, São Paulo: Ed. Malheiros, 2020.

TOFFLER, Alvin - A Terceira Onda. 6ª ed. Rio de Janeiro: Ed. Record, 1980. 